\title{
Inequalities in health within the health sector
}

\author{
R Balarajan
}

\begin{abstract}
Mortality among men employed in the health sector was examined using data surrounding the 1971 (1970-2) and $1981(1979-83)$ censuses to assess the differences between social classes in the health service and to study changes over a decade. Relative to men in England and Wales, mortality in the 1980s was significantly lower among dentists (standardised mortality ratio 66), doctors (69), opticians (72), and physiotherapists (79) and significantly higher among hospital porters (151), male nurses (118), and ambulancemen (109). Mortality from lung cancer among hospital porters (185) was more than fivefold that seen in doctors (33) and dentists (37). Ischaemic heart disease varied twofold, being lowest in dentists (60) and doctors (70) and highest in hospital porters (138). Over the decade mortality from lung cancer and ischaemic heart disease declined in all groups except hospital porters, ambulancemen, and orderlies. Most groups showed excess deaths from suicides and cirrhosis of the liver. Differences in mortality between health workers in social class I and those in social class IV widened between the 1970 s and 1980s and to a greater extent than among the general population.

The high mortality of some groups within the NHS, and the fact that differentials between social classes have widened more than in the general population, suggest that the NHS needs to pay more attention to the health of its own staff.
\end{abstract}

\section{Introduction}

The National Health Service is one of Europe's largest employers, with staff ranging from professionals to manual workers. The debate on widening inequalities in health ${ }^{1.3}$ encouraged me to examine trends in mortality among occupations in the health sector. Because the NHS is uniquely placed to improve the health of its employees through health promotion and by enabling early and ready access to health care, inequalities within the service should be minimal compared with those in the rest of the population. As well as examining differentials in mortality between occupational groups in the health sector, I also compared the differentials between the 1970s and the 1980 s.

\section{Methods}

Deaths among male doctors, dentists, pharmacists, opticians, nurses, radiographers, physiotherapists, chiropodists, porters, ambulance crews, and orderlies were compared with those among the general population of the same social class for 1970-2 and for 1979-83. The years studied were those surrounding the 1971 and 1981 censuses; the former covered deaths during $1970-2^{4}$ and the latter deaths during 1979-80 and $1982-3^{5}$ (data for 1981 were not available owing to industrial action by registrars). The occupations were coded to the respective classifications of the time. ${ }^{6}$

The data for 1970-2 did not allow porters, ambulancemen, and orderlies to be examined separately, so they were combined for the analysis of trends and are referred to as hospital manual workers. Deaths among this group were compared with those in social class IV for both periods, although some members of these occupations had been reallocated to social class IIIM by 1979 .

The causes of death examined were all cancers; cancer of the lung; ischaemic heart disease; cerebrovascular disease; bronchitis, emphysema, and asthma; cirrhosis of the liver; and suicide. The underlying causes of death were coded to the eighth and ninth revisions (for 1970-2 and 1979-83 respectively) of the International Classification of Diseases. ${ }^{89}$

Standardised mortality ratios were computed for the various occupational groups, social classes, and causes of death for 1970-2 and 1979-83. This was done by applying the rates prevalent in England and Wales in $1979-83$ in male age groups (10 year age groups to age 74) and for specific causes as standard to the respective populations. This permitted cause specific mortality to be examined between occupations, social classes, and over time. Class differences in mortality were explored by calculating differences between the standardised mortality ratios for social classes I and IV, both for the male population of England and Wales and for occupations in the health sector. Social class IV was selected rather than class $\mathrm{V}$ because most manual workers in the health sector are allocated to class IV.

$\chi^{2}$ Tests were performed to indicate the significance of the differences between the two periods. Ninety five per cent confidence intervals were calculated for the 1979-83 standardised mortality ratios to test the deviation from the standard and are presented for all cause mortality. Significance at the $5 \%$ level is denoted for all other causes for ease of presentation.

\section{Results}

There were 8665 deaths among male health workers in 1979-83 and 6297 in 1970-2. Deaths among radiographers, physiotherapists, and chiropodists were too few to examine cause-specific trends in these groups.

\section{ALL CAUSE MORTALITY}

In 1979-83 mortality was lowest among dentists, doctors, and opticians and highest among porters, male nurses, and ambulancemen (table I). Mortality among pharmacists, male nurses, and porters was higher than that of their social classes, the reverse being true of doctors, dentists, and opticians.

Over the decade mortality declined in most groups. In the 1970s dentists, doctors, and opticians experienced higher mortality than social class I as a whole but showed a greater decline to levels lower than social class I in the 1980 s (fig 1). Although pharmacists experienced a $25 \%$ decline in mortality, their level in the 1980s was still higher than that of social class I in the 1970s. The percentage decline among male nurses and radiographers exceeded that for their class, but mortality among nurses in the 1980 s remained higher than levels in social class II in the 1970s. Physiotherapists and chiropodists showed less improvement than social class II. Mortality among hospital manual workers declined by $9 \%$ over the 
decade but in 1979-83 was still higher than that in social class IV in 1970-2.

Absolute differences in standardised mortality ratios between social classes I and IV in England and Wales

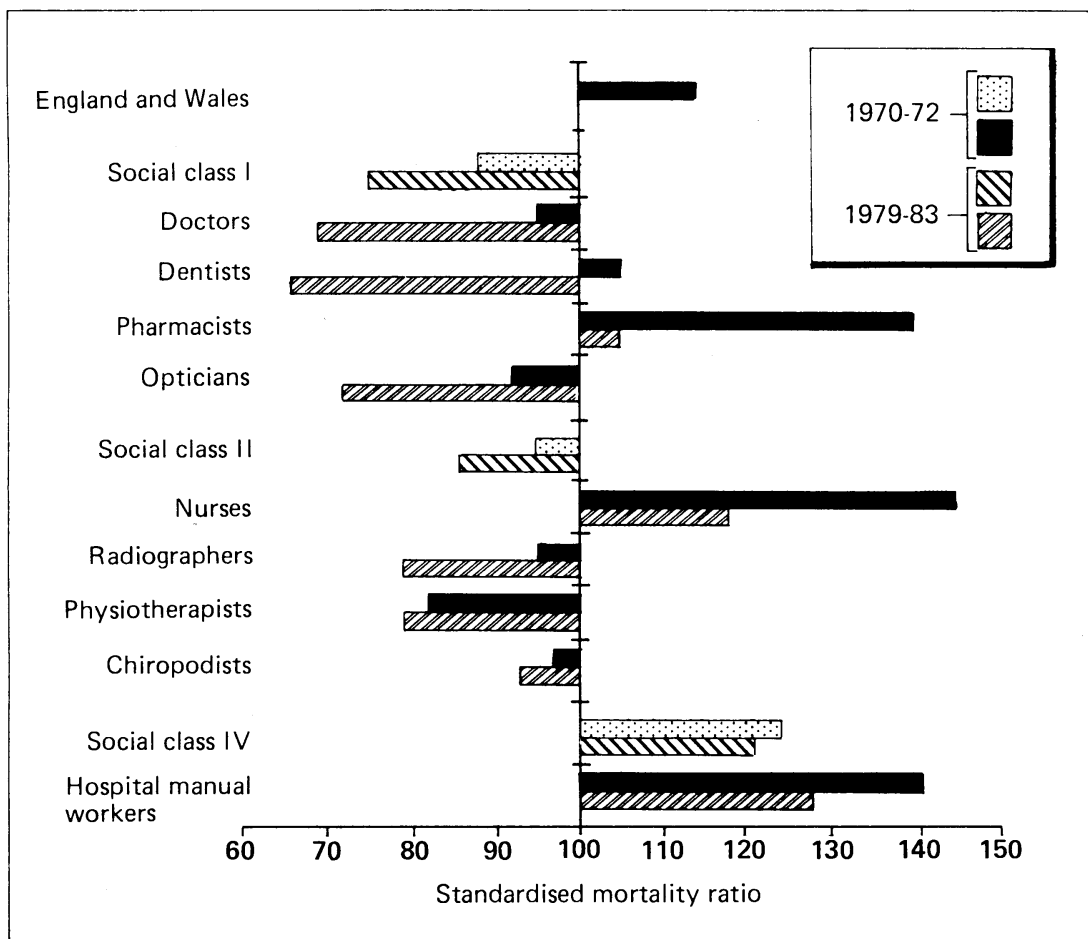

FIG 1-All cause mortality by occupation and social class for men in England and Wales in 1970-2 and 1979-83. Standardised mortality ratio for men aged 16-74 in England and Wales in 1979-83=100

TABLE I - All cause mortality by occupation and social class for men in England and Wales in 1979-83

\begin{tabular}{lcrc}
\hline & $\begin{array}{c}\text { Standardised } \\
\text { mortality ratio }^{\star}\end{array}$ & $\begin{array}{c}\text { Observed } \\
\text { deaths }\end{array}$ & $\begin{array}{c}95 \% \\
\text { Confidence interval }\end{array}$ \\
\hline Social class I: & 75 & 20285 & 74 to 76 \\
Doctors & 69 & 1565 & 65 to 72 \\
Dentists & 66 & 360 & 59 to 73 \\
Pharmacists & 105 & 893 & 98 to 112 \\
Opticians & 72 & 222 & 63 to 82 \\
Social class II: & 86 & 113194 & 85 to 86 \\
Nurses & 118 & 1882 & 113 to 123 \\
Radiographers & 79 & 49 & 59 to 105 \\
Physiotherapists & 79 & 76 & 62 to 99 \\
Chiropodists & 93 & 161 & 79 to 109 \\
Social class IV: & 121 & 145013 & 121 to 122 \\
Porters & 151 & 2106 & 145 to 158 \\
Ambulancemen & 109 & 714 & 101 to 117 \\
Orderlies & 98 & 637 & 91 to 106 \\
Hospital manual & & & \\
$\quad$ workerst & 128 & 3457 & 124 to 133 \\
\hline
\end{tabular}

${ }^{\star}$ Men aged 16-74, England and Wales, 1979-83=100.

†Porters, ambulancemen, and orderlies combined. increased from 36 in the 1970s to 46 in the 1980s. In contrast, differences in standardised mortality ratios between health sector staff in social classes I and IV increased from 35 to 52 (see table III).

\section{SELECTED CAUSES OF MORTALITY}

Table II shows standardised mortality ratios for selected causes of death in 1979-83. For all cancers, lung cancer, ischaemic heart disease, and cerebrovascular disease figure 2 shows the levels in 1970-2 and 1979-83 and table III summarises changes in mortality between social classes I and IV in the population of England and Wales and in the health sector.

TABLE III-Social class inequalities in selected causes of death differences in standardised mortality ratios between social class I and social class $I V$ in 1970-2 and 1979-83 in England and Wales and health sector (males)

\begin{tabular}{lcccccc}
\hline & \multicolumn{2}{c}{ England and Wales } & & \multicolumn{2}{c}{ Health sector } \\
\cline { 2 - 3 } \cline { 6 - 7 } \cline { 5 - 6 } & $1970-2$ & $1979-83$ & & $1970-2$ & $1979-83$ \\
\hline All cause mortality & 36 & 46 & & 35 & 52 \\
Cancer & 36 & 46 & & 42 & 65 \\
Lung cancer & 66 & 80 & & 72 & 97 \\
Ischaemic heart disease & 14 & 36 & & 13 & 46 \\
Cerebrovascular disease & 36 & 45 & & 24 & 57 \\
& & & & & &
\end{tabular}

All cancers, lung cancer, ischaemic heart disease, cerebrovascular disease, and bronchitis

For all the selected causes of mortality except cirrhosis and suicide the pattern in 1979-83 was similar to that for all cause mortality. Doctors, dentists, and opticians showed significantly reduced standardised mortality ratios, lower than those for social class I as a whole, whereas pharmacists had higher mortalities than social class I as a whole. At the other extreme, porters showed consistently high mortality, higher than that for social class IV as a whole. Likewise, nurses had higher standardised mortality ratios than social class II as a whole. Radiographers had lower standardised mortality ratios than social class II except for bronchitis, emphysema, and asthma, for which they had the highest mortality.

For all cancers, lung cancer, ischaemic heart disease, cerebrovascular disease, and bronchitis mortality generally declined in most groups between 1970-2 and 1979-83 (fig 2). Notable exceptions occurred in opticians, who showed no change in mortality from all cancers, and hospital manual workers, who showed a $10 \%$ increase in mortality from all cancers and a $3 \%$ increase in mortality from lung cancer. Nurses, who had a similar mortality to hospital manual workers in 1970-2 from all cancers and lung cancer, showed a large decline in mortality from both. Nevertheless, nurses'

TABLE II-Mortality from selected causes by occupation and social class for men in England and Wales in 1979-83. Standardised mortality ratio (SMR) for men aged 16-74 in England and Wales in 1979-83=100

\begin{tabular}{|c|c|c|c|c|c|c|c|c|c|c|c|c|c|c|}
\hline & \multicolumn{2}{|c|}{$\begin{array}{c}\text { All } \\
\text { cancers }\end{array}$} & \multicolumn{2}{|c|}{$\begin{array}{l}\text { Lung } \\
\text { cancer }\end{array}$} & \multicolumn{2}{|c|}{$\begin{array}{l}\text { Ischaemic } \\
\text { heart } \\
\text { disease }\end{array}$} & \multicolumn{2}{|c|}{$\begin{array}{c}\text { Cerebrovascular } \\
\text { disease }\end{array}$} & \multicolumn{2}{|c|}{$\begin{array}{l}\text { Bronchitis, } \\
\text { emphysema, and } \\
\text { asthma }\end{array}$} & \multicolumn{2}{|c|}{$\begin{array}{l}\text { Cirrhosis of } \\
\text { liver }\end{array}$} & \multicolumn{2}{|c|}{ Suicide } \\
\hline & SMR & $\begin{array}{c}\text { Observed } \\
\text { deaths }\end{array}$ & SMR & $\begin{array}{c}\text { Observed } \\
\text { deaths }\end{array}$ & SMR & $\begin{array}{c}\text { Observed } \\
\text { deaths }\end{array}$ & SMR & $\begin{array}{c}\text { Observed } \\
\text { deaths }\end{array}$ & SMR & $\begin{array}{c}\text { Observed } \\
\text { deaths }\end{array}$ & SMR & $\begin{array}{c}\text { Observed } \\
\text { deaths }\end{array}$ & SMR & $\begin{array}{c}\text { Observed } \\
\text { deaths }\end{array}$ \\
\hline Social class I: & $76^{\star}$ & 5730 & $50^{\star}$ & 1511 & $81^{\star}$ & 7637 & $77^{\star}$ & 1507 & $39^{\star}$ & 413 & 104 & 194 & $88^{\star}$ & 447 \\
\hline Doctors & $66^{\star}$ & 421 & $33^{\star}$ & 85 & $70^{\star}$ & 557 & $71^{\star}$ & 119 & $28^{\star}$ & 26 & $177^{\star}$ & 26 & $172^{\star}$ & 64 \\
\hline Dentists & $69^{\star}$ & 106 & $37^{\star}$ & 23 & $60^{\star}$ & 115 & $62^{\star}$ & 25 & $32^{\star}$ & 7 & 165 & 6 & $222^{\star}$ & 20 \\
\hline Pharmacists & 91 & 219 & $75^{\star}$ & 74 & 109 & 321 & 103 & 71 & 80 & 31 & $254^{\star}$ & 11 & $242^{\star}$ & 22 \\
\hline Opticians & $73^{\star}$ & 63 & $62^{\star}$ & 22 & $78^{\star}$ & 83 & $53^{\star}$ & 13 & $36^{\star}$ & 5 & & & 83 & 3 \\
\hline Social class II: & $86^{\star}$ & 32040 & $73^{\star}$ & 10893 & $92^{\star}$ & 42980 & $87^{\star}$ & 8471 & $61^{\star}$ & 3282 & $115^{\star}$ & 998 & $82^{\star}$ & 1721 \\
\hline Nurses & 108 & 477 & 96 & 169 & $123^{\star}$ & 671 & 113 & 134 & 106 & 69 & 121 & 12 & $201^{\star}$ & 59 \\
\hline Radiographers & 64 & 11 & 58 & 4 & 76 & 16 & 45 & 2 & 200 & 5 & & & 261 & 3 \\
\hline Physiotherapists & 66 & 18 & 79 & 9 & 91 & 31 & $26^{\star}$ & 2 & 23 & 1 & 193 & 1 & & \\
\hline Chiropodists & 81 & 40 & 78 & 16 & 101 & 62 & 89 & 12 & 105 & 8 & 106 & 1 & 179 & 3 \\
\hline Social class IV: & $122^{\star}$ & 40979 & $130^{\star}$ & 17957 & $117^{\star}$ & 48872 & $122^{\star}$ & 11043 & $144^{\star}$ & 7315 & 107 & 747 & $116^{\star}$ & 1796 \\
\hline Porters & $164^{\star}$ & 652 & $185^{\star}$ & 303 & $138^{\star}$ & 683 & $155^{\star}$ & 162 & $193^{\star}$ & 114 & $232^{\star}$ & 19 & $184^{\star}$ & 30 \\
\hline Ambulancemen & $127^{\star}$ & 233 & 114 & 83 & $116^{\star}$ & 266 & 104 & 49 & 89 & 23 & 22 & 1 & 77 & 9 \\
\hline Orderlies & 88 & 162 & 77 & 58 & 99 & 226 & 111 & 55 & 93 & 26 & 162 & 6 & 144 & 11 \\
\hline Hospital manual workers & $137^{\star}$ & 1047 & $142^{\star}$ & 444 & $123^{\star}$ & 1175 & $132^{\star}$ & 266 & $145^{\star}$ & 163 & $159^{\star}$ & 26 & $141^{\star}$ & 50 \\
\hline
\end{tabular}

${ }^{\star} \mathrm{p} \leqslant 0 \cdot 05$. Difference from standard 


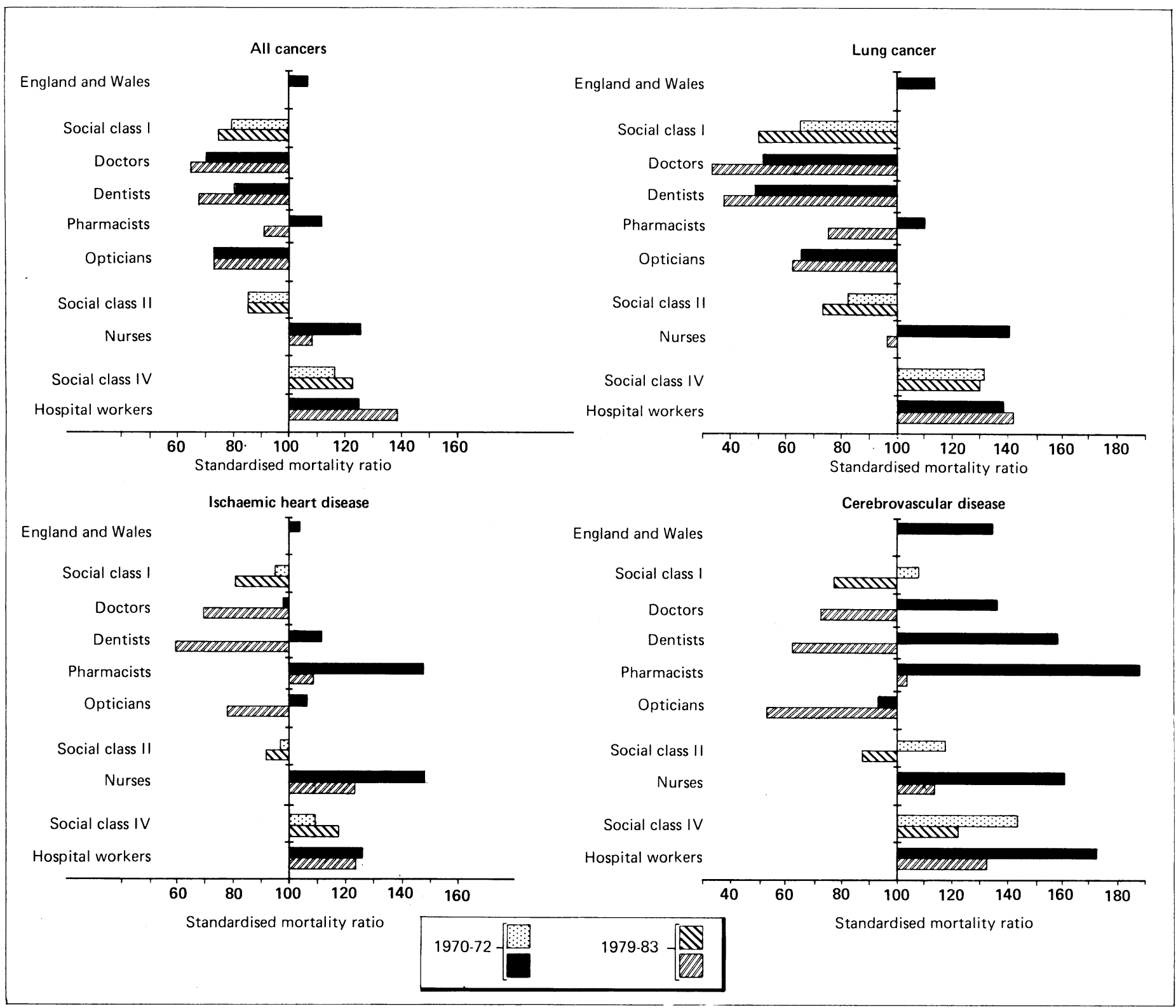

FIG 2-Mortality from all cancers, lung cancer, ischaemic heart disease, and cerebrovascular disease by occupation and social class for men in England and Wales in $1970-2$ and 1979-83. Standardised mortality ratio for men aged 16-74 in England and Wales in 1979-83=100

standardised mortality ratios for cancer and ischaemic heart disease in the 1980s remained higher than those for their social class in the 1970s. Pharmacists showed the greatest percentage decline in mortality from cancer in social class I, but their mortality in the $1980 \mathrm{~s}$ was still higher than that of social classes I and II in the 1970s. Hospital manual workers were the only group to show no reduction in mortality from ischaemic heart disease between the 1970s and the 1980s, though they did not reflect the rise in social class IV as a whole. For cancer, lung cancer, ischaemic heart disease, and cerebrovascular disease, however, mortality was higher among hospital manual workers than in social class IV.

\section{Cirrhosis of the liver}

In the 1980s mortality from cirrhosis was high in most health occupations, being highest in pharmacists, porters, and doctors (table II). Over the decade mortality increased among all groups except doctors.

\section{Suicide}

Likewise, the proportion of suicides was high in most health occupational groups in the 1980s and higher than in their respective social classes. Only ambulancemen and opticians did not show an excess. Over the decade there was, however, a significant decline in suicides among doctors (of 33\%), with dentists and hospital manual workers showing an increase.

\section{Discussion}

The major limitation of this study was the exclusion of women, since the NHS is one of Britain's largest employers of women. Women's occupations are, however, often not recorded at death so reliable data were not available. ${ }^{10} \mathrm{~A}$ further limitation is that occupational mortality analysis based on the last occupation before death is less likely to reflect cumulative occupational exposure for manual workers than for professional workers. Nevertheless, the position of the NHS as a near monopoly employer of health sector workers provided an ideal opportunity to assess the effects of working for a health oriented organisation on the health of its workers.

The study showed significant differences in mortality among men in health related occupations. Social class inequalities in mortality within the health sector not only widened over the decade but did so by more than the amount in the general population and by 1979-83 were greater than those in the general population.

The greatest falls in overall mortality were seen among doctors and dentists. They have high socio- 
economic status, ready access to medical care, and are more likely to adopt a healthy lifestyle, all of which contribute to their lower overall mortality. Studies from other countries have also shown lower overall mortality among doctors than in the general population ${ }^{11-1}$ but not always when compared with other professional groups. $12:$ The findings of greater falls in moriality from lung cancer, heart disease, and bronchitis in these professionals than in social class I or the overall population is further evidence of shifts in smoking habits, possibly influenced by the studies of Doll and Hill. ${ }^{1 \times-20}$

On the other hand, medical professionals face occupational hazards which result in higher mortality from other causes. Drug abuse, alcoholism, and suicide are serious occupational risks, ${ }^{21-24}$ reflected in the high rates of suicide and cirrhosis seen among doctors and dentists in this study. Higher rates of suicide among doctors have been reported from some other countries, ${ }^{1+1}+21: 4$ although data for Finland covering 1953-80 did not show a significant excess. ${ }^{112}$ The highest levels of cirrhosis and suicide were, however, seen among pharmacists, who also showed excess mortality from ischaemic heart disease and stroke, in contrast to the patterns seen in their social class.

At the other end of the scale mortality among hospital manual workers (porters, ambulancemen, and orderlies) was $28 \%$ higher than national levels and exceeded that of their social class. Moreover, their mortality fell by only $9 \%$ over the decade compared with falls of $37 \%$ in dentists, $27 \%$ in doctors, and $19 \%$ in male nurses, and their mortality in the $1980 \mathrm{~s}$ exceeded that of social class IV in the 1970s. Hospital workers showed an increase in mortality from cancer, cirrhosis, and suicide over the decade and virtually no improvement in mortality from ischaemic heart disease.

Although cause specific mortality was consistently high among hospital manual workers overall, porters, ambulancemen, and orderlies differed from each other. Porters suffered a significant excess of deaths from all the causes examined, whereas ambulancemen suffered excess deaths only from cancer and ischaemic heart disease. Ward orderlies experienced average mortality for causes other than cirrhosis and suicide. Porters mav select themselves into a hospital environment because of health needs, but their job demands that they should be generally fit. In contrast to orderlies they spend time away from patient areas and are thus able to lead a non-restrictive lifestyle with regard, for example, to smoking. Their coping mechanisms in facing illness may be poor compared with those of professionals, with adverse effects on their health. The increase in deaths from cancer, suicide, and cirrhosis, and the lack of decline in deaths from ischaemic heart disease in this group over the past decade are particularly disturbing.

Also disturbing are the high levels of mortality in male nurses. Despite a substantial decline over the decade, their mortality in the 1980 s was higher than that in social class II in the 1970s. They experienced higher mortality from cancer, ischaemic heart disease, stroke, and bronchitis than the population as a whole and also had high levels of suicide and cirrhosis, again probably reflecting the stress of their occupation. Male nurses are a heterogeneous group, with a substantial proportion of immigrants, who are traditionally drawn into psychiatry. Detailed studies with social profiles of study cohorts are required to explore the reasons behind these findings.

These high levels of mortality among health service staff and particularly the widening differentials between health workers in social class I and those in social class IV are a matter of concern. The National Health Service is under a special obligation to promote the health of its staff. Public health and occupational physicians should concern themselves with the problems within the organisation just as much as with those outside it, particularly in relation to nreventive medicine and health promotion.

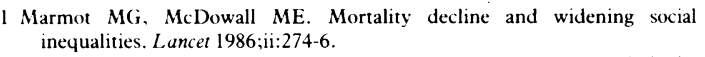

Marmot MG, McDowall ME. Mortality decline and widening social inequalities. Lancet 1986;ii:274-6.

2 Balarajan R, Yuen P, Machin D. Inequalities in health: changes in RHAs in the past decade. Br Med f 1987;294:1561-4

3 Balarajan R, McDowall ME. Regional socioeconomic differences in mortality among men in Great Britain today. Public Health 1988;102:33-43.

4 Office of Population Censuses and Surveys. Occupational mortality 1970-72: decennial supplement. London: HMSO, 1978. (Series DS No I.)

5 Office of Population Censuses and Surveys. Occupational mortality 1979-80, 1982-83: decennial supplement. London: HMSO, 1986. (Series DS No 6.)

6 (Office of Population Censuses and Surveys. Classification of occupations 1970. London: HMSO, 1970.

7 Office of Population Censuses and Surveys. Classification of occupations 1980 London: HMSO, 1980.

8 Anonvmous. Manual of the international statistical classification of diseases, injuries, and causes of death: 8th revision. Geneva: World Health Organisation, 1967.

9 Anonvmous. Manual of the international statistical classification of diseases, injuries and causes of death: 9 th revision. Geneva: World Health Organisation, 1977.

10 McDowall ME. Measuring women's occupational mortality. In: Population trends 34. Office of Population Censuses and Surveys. London: HMSO, 1983

11 Asp S, Hernberg S, Collan Y. Mortality among Finnish doctors, 1953-1972. Scand J Soc Med 1979;7:55-62.

12 Rimpela AH, Nurminen MM, Pulkkinen PO, Rimpela MK, Valkonen T. Mortality of doctors: do doctors benefit from their medical knowledge? Lancet 1987; $1: 84-6$

13 Goodman LJ. The longevity and mortality of American physicians. 1969-1973. Milhank Memorial Fund Quarterly 1975:53:353-75.

14 Enstrom JE. Trends in mortality among California physicians after giving up smoking: 1950-79. Br.Med f 1983;286:1101-5.

15 France $O$, Ugarte JM. Causes of death in physicians of Santiago, Chile. English summary.) Rev Med Chile 1977;105:792-801.

16 Bui-Dang-Ha Doan. Notes on physician mortality. (French) Cah Sociol Demogr Med 1977;17:73-6.

17 Araki S, Murata K, Kumagai K, Nagasu M. Mortality of medical practitioners in Japan: social class and the "healthy worker effect." Am $\mathrm{f}$ Ind Med 1986;10:91-9.

8 Doll $\mathrm{R}$, Hill AB. The mortality of doctors in relation to their smoking habits. Br.Med f $1954 ;$ i: 1451-5.

9 Doll R, Hill AB. Lung cancer and other causes of death in relation to smoking. Br.Med F 1956;ii:1071-81.

20 Doll R. Hill AB. Mortality in relation to smoking: ten years' observations of British doctors. Br Med F 1964;i:1399-410,1460-7.

21 Keeve JP. Physicians at risk: some epidemiologic considerations of alcoholism, drug abuse and suicide. 7 Occup Med 1984:26:503-8.

2 Roy A. Suicide in doctors. Psychiatr Clin North Am 1985;8:377-87.

23 a'Brook MF, Hailstone JD, McLauchlan IEJ. Psychiatric illness in the medical profession. Br f Psvchiatry 1967;113:1013-23.

24 Clever LH, Arsham GM. Physicians' own health $\rightarrow$ some advice for the advisors. West f Med 1984;141:846-54.

Accepted 7 fulv 1989
The "movement" in favour of shorthand for medical students is evidently not at all likely to be snuffed out by the extinguisher which the General Medical Council put upon Sir Dyce Duckworth's motion in favour of it. Those who believe in shorthand as a useful adjunct of medical study and practice are enthusiastic and energetic, and will probably have the success which their enthusiasm deserves. Opinion is not unanimous in support of their view, even among those physicians who have become accomplished in phonetic shorthand, and are past masters of Pitman's system. I have for the last twenty years got through nearly all my literary work and correspondence by the aid of dictation to a shorthand writer; indeed, for many years I have kept him constantly employed, and sigh at the thought of the ink shed and waste of paper of which I have been the vicarious cause. I am often surprised at the loss of time and exertion which men in large practice go through in writing with their own hand in lieu of dictation. I found when I was most busy in literary work that I could get through an average of two leaders a day and forty letters in a little over two hours. If I were to write them with my own hand this would involve at least four hours, probably five, of an exhausting combination of mechanical and mental work. I believe the time is not far off when men much employed in writing will do their work entirely by dictation to a phonographer. (British Medical fournal 1889;ii: 145) 